\title{
Caries risk and number of restored surfaces have impact on the survival of posterior composite restorations
}

\author{
Abstracted from \\ Opdam NJ, van de Sande FH, Bronkhorst E, et al. \\ Longevity of posterior composite restorations: a systematic review and meta-analysis. \\ J Dent Res 2014; 93: 943-949. \\ Address for correspondence: NJ Opdam, Radboud University Nijmegen Medical Centre, \\ College of Dental Sciences, Preventive and Restorative Dentistry, Ph van Leydenlaan 25, \\ PO Box 9101 6500HB Nijmegen, The Netherlands. E-mail: niek.opdam@radboudumc.nl
}

\section{Question: What factors affect the survival of posterior composite restorations?}

Data sources Cochrane Library, PubMed, the Web of Science (ISI) and Scopus.

Study selection Longitudinal studies of direct class II or classes I and II restorations in permanent dentition of at least five years duration, a minimum of 20 restorations at final recall and the original datasets available were considered. Only English language studies were included. Two reviewers screened titles independently.

Data extraction and synthesis Multivariate Cox regression method to analyse the variables of interest and hazard ratios with respective $95 \%$ confidence intervals were determined. The annual failure rate (AFR) of the investigated restorations and subgroups was calculated.

Results Twelve studies, nine prospective and three retrospective were included. A total of 2,816 restorations (2,585 Class II and 231 Class I restorations) were included in the analysis. Five hundred and sixty-nine restorations failed during the observation period, and the main reasons for failure were caries and fracture. Regression analyses showed a significantly higher risk of failure for restorations in highcaries-risk individuals and those with a higher number of restored surfaces. The overall annual failure rate at five years and ten years was $1.8 \%$ and $2.4 \%$ respectively. The rates were higher in high-caries-rate individuals at $3.2 \%$ and $4.6 \%$ respectively.

Conclusions The conclusion of the present meta-analysis of 12 clinical studies based on raw data is that caries risk and number of restored surfaces play a significant role in restoration survival, and that, on average, posterior resin composite restorations show a good survival, with annual failure rates of $1.8 \%$ at five years and $2.4 \%$ after ten years of service.

\section{Commentary}

A meta-analysis on a well conducted systematic review will often generate dependable evidence on the prognosis of dental treatment. Opdam et al. conducted a comprehensive systematic review with the aim of quantifying some prognostic risk factors on the long term survival of composite resin restorations on posterior teeth. ${ }^{1}$ The meta-analysis was conducted on individual patient data (IPD) rather than the more common standard aggregated data meta-analysis. A meta-analysis based on aggregated data statistically combines the distinct statistical outcome of all included studies to obtain a single summary estimate of the effects size and confidence that is representative of all the included studies. On the other hand, a meta-analysis based on individual patient data (IPD) seeks to combine the raw data of each patient from each individual study included in the review for traditional and more complex inferential statistical analysis. Although this approach is more rigorous, time consuming and expensive, if done well will often lead to more valid and accurate summary estimate, particularly for time-to-event studies (ie survival). ${ }^{2,3,4}$

However, an IPD methodology does come with its challenges, as evident in this review. For example, the authors were able to collect IPD from only 12 of the 25 studies that met the review's inclusion criteria. This included a total count of 2,685 individual posterior composite restorations to conduct a Kaplan-Meier survival analysis and a Cox regression analysis.

Results from this meta-analysis are summarised in the table below. On average $78 \%$ of the composite restorations on molars and $82 \%$ of the composite restorations on premolars continued to be clinically acceptable after ten years. This is equivalent to an estimated annual failure rate of $2.4 \%$ for all composite restorations on posterior teeth. The risk level of caries had a significant effect on the clinical survival of all posterior composite restorations.

Cox regression offers a qualitative description of how each risk factor plays on the survival of posterior composite restoration. This analysis generates the Hazard Ratio (HR) statistics. This is the relative risk that each factor has on the prognosis of a posterior composite restoration. For example, from the table, the reported HR of 3.04 indicates that the probability of a composite resin restoration failing in a high caries risk individual is 3.04 times more probable than an identical restoration in an individual with no risk to caries.

Not surprising is that multi-surface restorations do not usually last as long as a single surface restoration. However, an interesting finding is that lining a posterior resin restoration may compromise its longevity. This is consistent with a recently published study. ${ }^{5}$

The transference of these results to clinical practice must be taken with caution. Even the authors admit to biases that potentially occurred in the reported outcomes of each study and thus the meta-analysis conducted afterwards. For example, the authors were not able to get IPD from more than half of the 25 included studies. Also, heterogeneity between studies in the quality of the operator, the diagnosis of caries and the clinical threshold of when a restoration was considered unacceptable may threaten the validity and precision of these results. However, this is the first attempt to use IPD in a meta-analysis from a well conducted systematic review attempting to quantify the risk factors at play on the prognosis of 
posterior composite restorations. To quote the author; '... , the relevance of the present study is that it might bring us a step further in clarifying the overall picture on how long posterior composites survive and what factors may influence their survival' ${ }^{1}$

\section{Ben Balevi}

University of British Columbia, Vancouver, Canada

1. Opdam NJ, van de Sande FH, Bronkhorst E, et al. Longevity of posterior composite restorations: a systematic review and meta-analysis. I Dent Res 2014; 93: 943-949.

2. Thomas D, Radji S, Benedetti A. Systematic review of methods for individual patient data meta- analysis with binary outcomes. BMC Med Res Methodol 2014; 14: 79. doi: 10.1186/1471-2288-14-79.

3. Stewart LA, Tierney JF. To IPD or not to IPD? Advantages and disadvantages of systematic reviews using individual patient data. Eval Health Prof 2002; 25: 76-97.

4. Stewart LA, Clarke MJ. Practical methodology of meta-analyses (overviews) using updated individual patient data. Cochrane Working Group. Stat Med 1995; 14: 2057-2079.

5. Pallesen U, van Dijken JW, Halken J, Hallonsten AL, Höigaard R, Longevity of posterior resin composite restorations in permanent teeth in Public Dental Health Service: a prospective 8 years follow up. J Dent 2013; 41: 297-306

Evidence-Based Dentistry (2014) 15, 118-119. doi:10.1038/sj.ebd.6401051
Table 1 Survival of Posterior Resin Restorations; Summary of some of the results from a meta- analysis of IPD'

\begin{tabular}{|c|c|c|c|c|}
\hline & & $\begin{array}{l}\text { All teeth } \\
\text { ( } \mathbf{N}=\text { restorations) }\end{array}$ & Molar * & Premolar * \\
\hline \multirow{3}{*}{ AFR (\%)\# } & All & $\begin{array}{l}2.4 \\
(N=2,816)\end{array}$ & & \\
\hline & High Caries Risk & $\begin{array}{l}4.6 \\
(N=547)\end{array}$ & & \\
\hline & Low Caries Risk & $\begin{array}{l}1.6 \\
(N=1,815)\end{array}$ & & \\
\hline \multirow{3}{*}{$\begin{array}{l}10 \text { Year } \\
\text { Cumulative } \\
\text { Survival Rate } \\
(\%)+\end{array}$} & All & & 78 & 82 \\
\hline & $\begin{array}{l}\text { High } \\
\text { Caries Risk }\end{array}$ & & 60 & 70 \\
\hline & Low Caries Risk & & 82 & 88 \\
\hline \multirow{3}{*}{$\begin{array}{l}\text { Cox Regression } \\
\text { (Hazard Ratio) }\end{array}$} & Caries Risk & & $\begin{array}{l}3.04 \\
{[2.21,4.17]^{\wedge}}\end{array}$ & $\begin{array}{l}2.44 \\
{[1.62,3.68]^{\wedge}}\end{array}$ \\
\hline & $\begin{array}{l}\text { Multi-Surface } \\
\text { Restoration }\end{array}$ & & $\begin{array}{l}1.24 \\
{[1.09,1.42]^{\wedge}}\end{array}$ & $\begin{array}{l}1.46 \\
{[1.22,1.75]^{\wedge}}\end{array}$ \\
\hline & Lined-Restoration & & $\begin{array}{l}2.87 \\
{[1.66,4.95]^{\wedge}}\end{array}$ & $\begin{array}{l}4.93 \\
{[2.24,10.85]^{\wedge}}\end{array}$ \\
\hline
\end{tabular}

\#- based on a 10 year follow up

${ }^{*}$ The number of molars and premolars included in the analysis were not reported

+ Visual estimate from provided Meier - Kaplan survival graphs

95\% Confidence Interval 